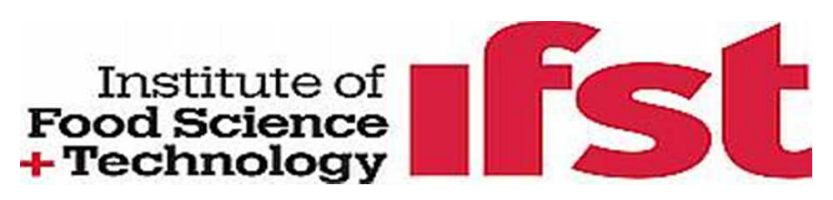

\title{
From wheat sourdough to gluten-free sourdough: a non- conventional process for producing gluten-free bread
}

\begin{tabular}{|c|c|}
\hline Journal: & International Journal of Food Science and Technology \\
\hline Manuscript ID: & Draft \\
\hline Manuscript Type: & Original Manuscript \\
\hline Date Submitted by the Author: & $\mathrm{n} / \mathrm{a}$ \\
\hline Complete List of Authors: & $\begin{array}{l}\text { Marti, Alessandra; Università degli Studi di Milano, DeFENS, Department of } \\
\text { Food, Environmental and Nutritional Sciences } \\
\text { Bottega, Gabriella; Università degli Studi di Milano, DeFENS, Department of } \\
\text { Food, Environmental and Nutritional Sciences } \\
\text { Franzetti, Laura; Università degli Studi di Milano, DeFENS, Department of } \\
\text { Food, Environmental and Nutritional Sciences } \\
\text { Morandin, Francesca; Università degli Studi di Milano, DeFENS, Department } \\
\text { of Food, Environmental and Nutritional Sciences } \\
\text { Quaglia, Lucio; Molino Quaglia, } \\
\text { Pagani, M. Ambrogina; Università degli Studi di Milano, DeFENS, } \\
\text { Department of Food, Environmental and Nutritional Sciences }\end{array}$ \\
\hline Keywords: & Cereals and Grains, Pasta, Baking \\
\hline
\end{tabular}




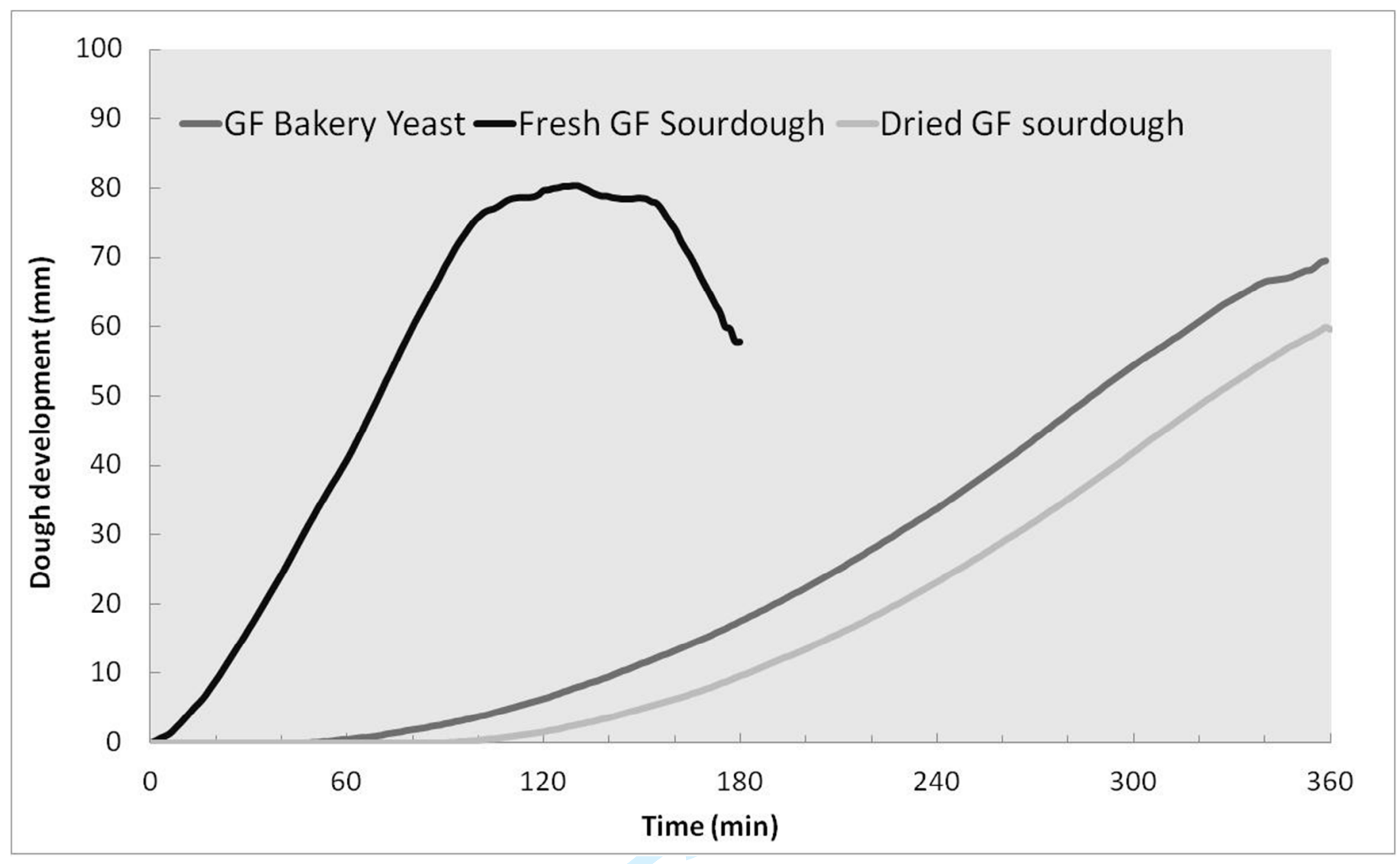

graphical abstract 
1 From wheat sourdough to gluten-free sourdough: a non-conventional process for producing

2

gluten-free bread

3

$4 \quad$ Alessandra Marti ${ }^{1}$, Gabriella Bottega ${ }^{1}$, Laura Franzetti ${ }^{1}$, Francesca Morandin ${ }^{1}$, Lucio

5 Quaglia $^{2}$, Maria Ambrogina Pagani ${ }^{1} *$

6

$7 \quad{ }^{1}$ Università degli Studi di Milano - Department of Food, Environmental and Nutritional

8 Sciences - via Giovanni Celoria 2, 20133 Milan, Italy

$9 \quad{ }^{2}$ Molino Quaglia S.p.A., 6, Via Roma, 35040 Vighizzolo D’Este, Italy

10

$11 *$ Corresponding author:

12 Prof. Maria Ambrogina Pagani

13 2, Via G. Celoria

1420133 Milan, Italy

15 E-mail: ambrogina.pagani@unimi.it

16 Phone: +390250316658

17 
1

2

3

4

5

6

7

8

9

10

\begin{abstract}
18 Abstract
19 Gluten-free (GF) sourdough was prepared from wheat sourdough, and analyzed both in fresh 20 (GFS) and dried forms (DGFS). The gluten content in each GF sourdough sample was less 21 than $20 \mathrm{mg} / \mathrm{kg}$. The dough leavening capacity and the properties of the bread samples were 22 investigated and compared to those of bread prepared using bakery yeast (Saccharomyces 23 cerevisiae). In GFS, Lactic Acid Bacteria (LAB) and yeasts were found in amounts 24 corresponding to $10^{8}$ and $10^{7} \mathrm{CFU} / \mathrm{g}$, respectively; whereas, both LAB and yeasts were 25 detected in lower amounts (about $10^{6} \mathrm{CFU} / \mathrm{g}$ ) in DGFS. When used in bread-making, both 26 GFS types produced significant dough acidification and exhibited good dough development 27 during proofing, resulting in loaves with specific volume values between 3.00 and $4.12 \mathrm{ml} / \mathrm{g}$, 28 values similar to those obtained for reference bread $(3.05 \div 4.15 \mathrm{ml} / \mathrm{g})$. The use of GFS was 29 effective in lowering the bread staling rate during storage for up to 7 days.

31 Keywords: gluten-free sourdough, gluten-free bread, dough leavening, rheofermentometer, 32 bread staling.

(r) 


\section{Introduction}

Celiac disease is one of the most common lifelong disorders affecting approximately $1 \%$ of the world's population (Catassi and Fasano, 2008). Since the removal of gluten from the diet results in an improvement in the clinical symptoms of celiacs, the consumption of wheat, barley and rye-based products should be avoided in a gluten-free (GF) diet.

The growing interest in GF foods has stimulated the creation of products that meet the needs of celiacs and their families, as well as those of a large number of consumers who have decided to exclude gluten from their diet for reasons of health benefits. Despite a wide variety of breads made from rice, corn, and other GF flours currently available on the market, most of these products are poor in quality (low specific volume, high crumb hardness and crumbling), particularly when compared with their wheat counterparts (Hager et al., 2012). Indeed, gluten is responsible for the unique viscoelastic properties (extensibility, resistance to deformation, mixing tolerance and gas-holding capacity) of wheat dough. Consequently bread represents the most challenging GF products to formulate and produce, as gluten is its architectural key. In the past decades, several approaches have been investigated - and recently reviewed by Houben et al. (2012) - for the development of GF baked products, such as the use of: $i$ ) different GF flours (rice, sorghum, oat, buckwheat, amaranth, quinoa, teff, corn); ii) ingredients/additives (starches, dairy products, egg proteins, dietary fibre, gum and hydrocolloids); iii) alternative technologies such as physical, enzymatic or microbic preprocessing. As regards the last approach, it has already been proved that the use of sourdough in GF bread improves bread texture, extends shelf life and is more flavorful (Zannini et al., 2012). Although the positive contribution of sourdough could produce high quality GF bread, only a few attempts have been made to produce GF sourdoughs and characterize their functional properties. To the best of our knowledge, all these studies investigated the development of sourdoughs from GF cereals or pseudocereals either using selected starter 
cultures (Sanni et al., 1998; Schober et al., 2007; Edema and Sanni, 2008) or by spontaneous

60 fermentation of strains isolated from the GF flours (Moore et al., 2007, 2008; Di Cagno et al.,

61 2008; Vogelmann et al., 2009). Exogenous starter cultures are less suitable for the

62 fermentation of GF materials, since the adaptability of the starter strains to the GF sourdoughs

63 is greatly influenced not only by technological parameters but also by the flour and the

64 interactions between starter microorganisms and natural microbiota (Vogelmann et al., 2009;

65 Moroni et al., 2010a, b). The second approach - fermentation of strains isolated from GF

66 flours - involves specific skills, difficult to be transferred to an industrial scale. Finally, Di

67 Cagno et al., (2002) showed that selected LAB, possessing proteolytic activities, could

68 efficiently hydrolyze the toxic peptides of gliadin in wheat sourdough. Breads produced with

69 this sourdough approach exhibited acceptable quality and resulted in no alterations to baseline

70 values of celiac individuals when consumed (Di Cagno et al., 2004). Even if prolonged

71 sourdough fermentation of wheat using specific LAB represents an interesting alternative

72 technology for baking good-quality breads that can be consumed by celiacs, food industries

73 will have to face the obstacle of winning the acceptance of consumers for GF products

74 containing detoxified wheat (Moroni et al., 2009).

75

76

77
Thus, considering the issues related to the current approaches used for sourdough preparation, the aim of this study was: $i$ ) to propose a method for producing GF sourdough directly from a conventional and strengthened wheat sourdough, removing gluten and, at the same time, maintaining the LAB and yeasts originally present in the wheat sourdough; $i$ ) to verify whether the use of the GF sourdough - either fresh or after drying - could improve the characteristics of GF bread prepared without further addition of Saccharomyces cerevisiae.

To better understand the effects and the possible benefits of baking with sourdough, the characteristics of GF bread samples were compared with those of a reference bread made with commercial bakery yeast and the same GF flour mixture. 
Materials and Methods

86

87

GF flours

88

Two commercial GF blends, labeled Mix A and Mix B, differing in protein source, provided by Molino Quaglia S.p.A. (Vighizzolo D’Este, Italy), were used for preparing GF bread. As reported on their labels, Mix A was composed of rice flour, wheat starch, powder milk, sugar, guar flour, and psyllium; Mix B contained rice flour, wheat starch, buckwheat flour (37\%),

93 powder milk, sugar, guar flour, and psyllium.

94 The composite traits of GF flours are shown in Table 1. Starch and soluble sugars, proteins, 95 and total dietary fibre were determined according to the approved methods AACC 44-15, 7613, 46-12, and 32-05.01 respectively (AACC, 2001).

GF Sourdough preparation

99

100 Fresh Gluten free sourdough (GFS) was prepared using a GF inoculum obtained directly from

101 a conventional wheat sourdough (WS). WS was maintained in spring water for 24 hours at

102 room temperature; after that it was removed and the water was added to mix A or mix B

103 (water:flour ratio $=60: 100)$. After a first dough fermentation step ( 24 hours at $20^{\circ} \mathrm{C}$ ), fresh

104 spring water and GF flour were added to the fermented dough, and the resultant dough was

105 fermented for 24 hours at $20^{\circ} \mathrm{C}$. The refreshment step was daily repeated at least 5 times,

106 obtaining GF inoculum (GFI) and continued until use. GFI was used as such or after drying

$107\left(30^{\circ} \mathrm{C}\right.$ for $\left.36 \mathrm{~h}\right)$, resulting in a dried GF inoculum (DGFI).

108

109 GF bread-making

110 
111 From fresh Gluten-Free Sourdough (GFS)

112

113 GFI was mixed with GF flour (mix A or mix B; GFI: GF flour ratio of $100: 100$ ) and to water

114 (GFI:water ratio of $100: 70)$ (Fig. 1a). A first fermentation stage was carried out for 3 hours

115 in an proofing chamber at $30{ }^{\circ} \mathrm{C}$ and $85 \% \mathrm{RH}$. The refreshment step was carried out twice,

116 obtaining $\mathrm{GFI}_{2}$ which was added to flour $\left(\mathrm{GFI}_{2}: \mathrm{GF}\right.$ flour ratio of $\left.100: 500\right)$ and water

$117\left(\mathrm{GFI}_{2}\right.$ :water ratio of 100:400), and the fermentation stage was carried out for 15 hours at room 118 temperature $\left(\mathrm{GF}_{3}\right)$. After that, the dough was added to GF mix A or GF mix B $\left(\mathrm{GFI}_{3}: \mathrm{GF}\right.$ flour 119 ratio of 100: 40) and water $\left(\mathrm{GFI}_{3}:\right.$ water ratio of $\left.100: 50\right)$, and mixed in an automatic spiral 120 mixer (Bomann, Clatronic s.r.l., Italy), for $9 \mathrm{~min}$ at low speed and for $3 \mathrm{~min}$ at high speed.

121 Immediately after mixing, the dough was left to rest for $20 \mathrm{~min}$ at room temperature. The final

122 sourdough was labeled as Gluten-Free Sourdough (GFS). The dough was divided into

123 portions of $80 \mathrm{~g}$, moulded into cylinders, put into baking pans $(8 \times 4 \times 3.5 \mathrm{~cm})$ and left to rest in 124 a proofing chamber at $30{ }^{\circ} \mathrm{C}$ and $85 \% \mathrm{RH}$. The proofing time lasted 4 hours in the case of 125 GFS and DGFS; 45 min for BY. All the samples were baked for 1 hour at $185^{\circ} \mathrm{C}$ in an oven 126 (Self Cooking Center ${ }^{\circledR}$, Rational International AG), with vapour injection in the first 20 min 127 of baking (Fig. 1a). Two hours after/removal from the oven the samples were packaged in a 128 perforated OPP film and stored at controlled conditions $\left(20^{\circ} \mathrm{C}, 60 \% \mathrm{RH}\right)$ for seven days.

130 From Dried Gluten-Free Sourdough (DGFS)

132 The dried gluten-free inoculum (DGFI) was pre-fermented in water (DGFI:water ratio 100:30) 133 for 19 hours in a proofing chamber at $30{ }^{\circ} \mathrm{C}$ and $85 \% \mathrm{RH}$ (Fig. 1b). The resultant dough was 134 added to GF flour (mix A or mix B; $\mathrm{DGFI}_{2}: \mathrm{GF}$ flour ratio of 200:100) and water 135 (DGFI 2 :water ratio of 100:50) and the fermentation stage was carried out for 12 hours at room 136 temperature. The dough was added to GF flour $\left(\mathrm{DGFI}_{3}: \mathrm{GF}\right.$ flour ratio of 100:400) and water 
$137\left(\mathrm{DGFI}_{3}\right.$ :water ratio of 100:100) and mixed in an automatic spiral mixer (Bomann, Clatronic

138 s.r.l., Italy), for 9 min at low speed and for $3 \mathrm{~min}$ at high speed. Immediately after mixing, the

139 dough was left to rest for $20 \mathrm{~min}$ at room temperature. The final dough was labeled as Dried

140 Gluten-Free Sourdough (DGFS). It was transformed into GF bread by adopting the same

141 conditions described for GFS and showed in Fig. $1 \mathrm{~b}$.

142

143 From Bakery yeast (BY)

144

145 Mix A or mix B were mixed with bakery yeast (3g/100g flour) previously dissolved in water.

146 The GF blends/water ratio used for bread-making was 100:100 (Fig. 1c). As for GFS and

147 DGFS, BY was left to rest for 20 min at room temperature after mixing. It was transformed

148 into GF bread by adopting the same conditions described for GFS bread and showed in Fig.

$1491 \mathrm{c}$.

150

151 Sourdough characterization

152

153 Chemical characterization

154

155 Total titratable acidity (TTA) was determined on $10 \mathrm{~g}$ of sample homogenized with $90 \mathrm{ml}$ of

156 distilled water and expressed as the amount (ml) of $0.1 \mathrm{M} \mathrm{NaOH}$ to get $\mathrm{pH}$ of 8.5. The $\mathrm{pH}$

157 value was determined by a Crison GPL22 pH-meter (Crison Instruments, Alella, Barcelona, 158 Spain).

159

160 Microbial characterization

161 
162 Ten grams of dough sample was aseptically weighed and suspended in a sterile bag, mixed

163 with $90 \mathrm{~mL}$ of sterile $0.85 \%$ trypton salt solution and homogenized with a Stomacher

164 Calworth 400 Circulator (PBI International, Milan, Italy) at $230 \mathrm{rpm}$ for $1 \mathrm{~min}$. Tenfold

165 progressive dilutions were prepared and the following microbiological determinations were

166 performed: i) Total Bacterial Count (TBC) by pour plates on Plate Count Agar (PCA) (VWR

$167 \mathrm{GmbH}$, Darmstadt, Germany), incubation at $30^{\circ} \mathrm{C}$ for $48 \mathrm{~h}$ (ISO, 2003); ii) Total Lactic Acid

168 Bacteria (LAB) by pour plates on de Man Rogosa Sharpe agar MRS (Merck, Darmstadt,

169 Germany) incubation under anaerobic conditions (gas pack) at $30^{\circ} \mathrm{C}$ for $48 \mathrm{~h}$ (De Man et al.,

170 1960); iii) yeasts by spread technique on Yeast Glucose Chloramphenicole (YGC) incubation

171 at $30{ }^{\circ} \mathrm{C}$ for $48 \mathrm{~h}$ (ISO, 1992). All microbiological analyses were carried out in duplicate, and

172 the results were expressed as the mean CFU per gram.

173

174 Gluten content

175

176 The gliadin content measurement was carried out by using a monoclonal R5-antibody-based

177 sandwich enzyme-linked immunosorbent assay (ELISA), RIDASCREEN® Gliadin test kit

178 (R-Biopharm AG, Darmstadt, Germany). Assays were performed according to the standard

179 procedures suggested by the kit supplier. An aliquot of $0.25 \mathrm{~g}$ of dough was suspended in 2.5

$180 \mathrm{~mL}$ cocktail solution (6 M guanidine chloride and $100 \mathrm{mM}$ 2-mercaptoethanol) and shaken for

$18140 \mathrm{~min}$ at $50{ }^{\circ} \mathrm{C}$. The suspension was then centrifuged at $2500 \times \mathrm{g}$ for $10 \mathrm{~min}$. The clear

182 supernatant was directly used for immunoassay after 500-fold dilution with a proper dilution

183 buffer. Gliadin contents in all samples were detected in two duplicate and independent

184 measurements, using two different lots of the kit. The gluten content was expressed as the

185 duplicate of the detected gliadin value.

186

187 Dough characterization : rheofermentographic test 
189 The dough development and the gas volume produced by GFS, DGFS and BY activities were

190 assessed with a rheofermentometer (Chopin, Tripette \& Renaud, Villeneuve La Garenne

191 Cedex, France). Each dough was prepared as described in the "Bread preparation" section.

192 The rheofermentographic test was performed on $315 \mathrm{~g}$ portion of the dough and carried out at

$19330^{\circ} \mathrm{C}$ for $3 \mathrm{~h}$ when BY was used, and for $6 \mathrm{~h}$ when either GFS or DGFS was used. Maximum

194 dough height (Hm; mm), final height of dough (h; mm), maximum height of gaseous

195 production (H'm; mm), time when the porosity of the dough developed (Tx; min), total $\mathrm{CO}_{2}$

196 production $\left(\mathrm{CO}_{2}\right.$-TOT; $\left.\mathrm{ml}\right), \mathrm{CO}_{2}$ retained $\left(\mathrm{CO}_{2}-\mathrm{RET} ; \mathrm{mL}\right), \mathrm{CO}_{2}$ released $\left(\mathrm{CO}_{2}-\mathrm{REL}\right.$; $\left.\mathrm{mL}\right)$, and

$197 \mathrm{CO}_{2}$ retention coefficient $(\mathrm{RC}, \%)$ were determined.

198

199

200 Bread characterization

201

202 Weight, volume, and specific volume

203

204 The apparent volume $(\mathrm{n}=5)$ was determined by the rapeseed displacement method, two hours

205 after baking. The weight of the bread $(n=5)$ was recorded and the specific volume was

206 determined through the volume/mass ratio and expressed in $\mathrm{mL} / \mathrm{g}$.

208 Crumb moisture and water activity

210 The moisture of the crumb core was determined in triplicate using a single-stage drying

211 process for $16 \mathrm{~h}$ at $105^{\circ} \mathrm{C}$. The crumb core water activity (aw) was measured in triplicate by

212 an electronic hygrometer (Aqua Lab, CX-2 - Decagon Devices, Pullman, WA). 
216 Crumb texture characteristics were assessed using a dynamometer (Z005, Zwick Roell, Ulm, 217 Germany), equipped with a $100 \mathrm{~N}$ and $5 \mathrm{kN}$ load cell. The three central slices $(1.5 \mathrm{~mm}$ 218 thickness) of each loaf were compressed to $40 \%$ of their height to evaluate hardness, using a 219 cylindrical aluminum probe of $30 \mathrm{~mm}$ diameter and a test speed of $2 \mathrm{~mm} / \mathrm{s}$. Crumb hardness 220 was measured $(n=6)$ after $0,1,2$ and 7 storage days and expressed as the load $(\mathrm{N})$ at $30 \%$ 221 strain. The rate of staling was calculated as follows: (Firmness after $n$ days - initial Firmness)/ 222 initial Firmness; where $n$ represents the storage days.

Statistical analysis

The data were processed by Statgraphic Plus for Windows v. 5.1. (StatPoint Inc., Warrenton, 227 VA, USA). A one-way analysis of variance (Anova) was performed using the Least

Significant Differences (LSD) test to compare the sample means; differences were considered significant at $\mathrm{P}<0.05$.

230

\section{Results and Discussion}

Sourdough characterization

According to European legislation (EC, 2009) "Foodstuffs may bear the term gluten-

236 free if the gluten content does not exceed $20 \mathrm{mg} / \mathrm{kg}$ in the food as sold to the final consumer".

237 The process proposed here for preparing a gluten-free inoculum (GFI) from wheat sourdough

238 (WS) was effective not only in having a final value for gluten content lower than the legal

239 maximum amount allowed for GF products, but also in maintaining low $\mathrm{pH}$ and high acidity 
240 values in the dough in both GF sourdough types (Table 2). In fact, in GFI the LAB and yeast

241 amount was about $10^{8} \mathrm{UFC} / \mathrm{g}$ and $10^{7} \mathrm{CFU} / \mathrm{g}$, respectively, values very close with those

242 measured in WS (Table 2). The drying of GFI allowed the removal of more than $80 \%$ of the

243 water such as to guarantee the shelf-life of the product. As expected, drying of sourdough,

244 even if carried out at low temperatures $\left(30^{\circ} \mathrm{C}\right.$ for $\left.36 \mathrm{~h}\right)$ caused a lowering in microbial count

245 (Table 2) and, consequently, a lowering of its fermenting capacity. For this reason, when

246 dried starters are used for the sourdough process, the addition of $S$. cerevisiae is more and

247 more frequent in bread-making in order to promote dough development in an acceptable time

248 scale (Corsetti, 2013).

249

250 Dough leavening properties

251

252 The Rheofermentometer test provides information regarding the gas production and gas

253 holding capacity of dough, useful for predicting the fermentative properties of dough. The

254 rheofermentographic charts and indices of the GF dough samples are reported in Fig. 2 and

255 Table 3, respectively. In both GF mixtures, the presence of hydrocolloids (psyllium and guar

256 flour) assured the formation of a matrix with appropriate consistency for this type of dough

257 according to the farinographic test (150-175 BU). Indeed, a farinographic consistency equal to

$258200 \mathrm{BU} \pm 20$ was evidenced as the adequate condition to properly form a GF dough able to

259 sustain further transformations, particularly during leavening (Mariotti et al., 2009). The

260 increase in viscosity of the liquid phase, prevented starch and yeast sedimentation and bubble

261 coalescence during fermentation (Mariotti et al., 2013). Nevertheless, the leavening trend

262 differed according to the leavening agent and the GF recipe. As expected, the gaseous

263 production and the amount of $\mathrm{CO}_{2}$ produced during the leavening phase were higher in $\mathrm{BY}$

264 compared to those prepared with GFS or DGFS (Table 3). In particular, the development of

265 BY dough (Tx, i.e. the moment in which the structure is no longer able to retain the $\mathrm{CO}_{2}$ ) 
reached the maximum in 120 and 76 minutes, according to the type of GF flour used - A and

B, respectively (Fig. 2). Then, this index remained constant and subsequently tended to decrease, following a physiological structural collapse of the dough, responsible for the release of carbon dioxide into the environment.

The development associated with the use of gluten-free sourdough, both GFS and

DGFS, markedly differed from that observed in the control (Fig. 2). In particular, the increase

272 in height of the dough containing GFS or DGFS did not show signs of structural failure; on the contrary, these samples were prone to a continuous upward trend even after six hours of fermentation. To summarize: the leavening trend in both sourdough systems was not only similar but also the same height was reached as in BY as long as an extension of proofing time was provided. In fact, at the end of the leavening (360 min), the GFS and DGFS dough exhibited higher (compared to BY) $\mathrm{CO}_{2}$ retention coefficients, indicating that significant dough expansion is ensured by slow and gradual $\mathrm{CO}_{2}$ formation. As is well-known, in glutenbased products, gas retention is strongly influenced by the viscoelastic properties of gluten proteins (Cauvain, 2012). In the GF formulations considered in this study, the presence of proteins from milk and/or buckwheat, as well as of hydrocolloids, positively affected $\mathrm{CO}_{2}$ retention ability. The absence of the Tx index in most of the GF dough samples - even after six hours of fermentation - was the result of a fairly compact mass because the absence of gluten which imparts viscoelastic properties to the dough. Hydrocolloids, in fact, provide proper consistency and compactness to withstand physical stresses but these additives lack the viscoelasticity typical of the gluten network (BeMiller, 2009). Our results agree with those reported in other studies: the time of appearance of the porosity in mixtures containing sourdough is superior to non-acid doughs (Dal Bello et al., 2007). Regarding the recipe, the presence of buckwheat flour negatively influenced dough leavening: $40 \%$ lower height in mix B compared to mix A. This result is likely due to a weakening of the protein network in the presence of buckwheat flour (Torbica et al., 2010). 
292 On the contrary, Mariotti et al. (2013) showed improvements in dough development with the

293 incorporation of buckwheat likely because of an increase in dough viscosity, as a consequence

294 of its high dietary fiber content.

295

296 Bread characteristics

297

298 The properties of GF breads obtained from the different leavening agents (BY, GFS, and

299 DGFS) are reported in Table 4. In agreement with the rheofermentometer data, the best bread-

300 making performances were obtained with mix A, which exhibited higher height and specific

301 volume indices than mix B. The presence of buckwheat flour, indeed, could enhance the

302 nutritional value of the bread but at the expense of poor bread volume, as referred by Moore

303 et al. (2004) and Moore et al. (2009). Despite that, the bread characteristics obtained for mix

304 B products were in the range of acceptable loaf volume, and comparable to those reported in

305 the literature (Mezaize et al., 2009; Mariotti et al., 2013).

306 Regardless of the mixture composition, bread samples prepared using BY or GFS did

307 not show significant differences $(p>0.05)$ in crumb moisture and water activity (Table 4$)$. The

308 bread development indices were in agreement with literature data (Moore et al., 2007;

309 Schober et al., 2007; Mariotti et al., 2013) and suggested that the sole use of GFS resulted in

310 bread with a specific volume comparable to that obtained using S. cerevisiae (Table 4). The

311 improvement of GF bread by sourdough was less noticeable when DGFS was used, thus

312 suggesting the need to combine the type of sourdough with bakery yeast.

313 As regards to crumb firmness, samples from mix B were characterized by a higher

314 initial consistency than samples from mix A (Table 4), probably due to the presence of

315 buckwheat. However, the use of this raw material induced a decrease in crumb softness, due

316 to its richness in non starch polysaccharides (Biacs et al., 2002). At the same time, the high

317 hydrophilic characteristics of fibre components resulted in a lower staling of the product 
318 over time (Fig. 3). The effect of using GFS on crumb texture during storage was more evident

319 when mix A was used. Although bread from sourdough fermentation exhibited higher initial

320 firmness compared to bread with $S$. cerevisiae, the use of either GFS or DGFS resulted in GF

321 breads characterized by longer shelf-life, in agreement with previous studies (Corsetti et al.,

322 1998; Corsetti et al., 2000; Schober et al., 2007).

323

324 Conclusions

325

326 The present study shows that it is possible to obtain GF sourdough from wheat sourdough,

327 suitable to produce bread without adding S. cerevisiae or selected cultures of LAB. It has been

328 proved that the use of the GF sourdough dried at low temperatures contains alive and vital

329 microbial strains (LAB and yeasts). The LAB and yeasts present in GF sourdough assured an

330 appropriate development of the dough during proofing, resulting in bread with a high specific

331 volume, similar to that observed when bread was prepared with BY only. Finally, the use of

332 GF sourdough, either as such or after partial dehydration, resulted in bread characterized by

333 better shelf-life over time, especially for the formulation composed mainly of starchy

334 material.

335

336 Acknowledgements

337

338 The Authors would like to thank Prof. Stefania Iametti and her team for gluten determination.

339 The Authors declare that there is no conflict of interest.

341 References

342 American Association of Cereal Chemists (AACC). (2001). Approved methods of the 343 AACC. St Paul, MN, USA. 
BeMiller, J. N. (2009). Hydrocolloids. In: Gluten-free cereal products and beverages

345 (edited by E. K. Arendt \& F. Dal Bello). Pp. 203-215. London, UK: Academic Press.

346 Biacs, P., Aubrecht, E., Leder, I., \& Lajos, J. (2002) Buckwheat. In: Pseudocereals

347 and less common cereals: grain properties and utilization (edited by P. S. Belton \& J.R:N.

348 Taylor). Pp. 123-151. Berlin, Germany: Springer-Verlag.

349 Catassi, C, \& Fasano A. (2008). Celiac disease. In: Gluten-free cereal products and

350 beverages (edited by E. K. Arendt \& F. Dal Bello). Pp 1-22). London, UK: Academic Press.

351 Cauvain, S. (2012). Breadmaking: an overview. In: Breadmaking - Improving quality

352 (edited by S.P. Cauvain). Pp. 9-32. Cambridge, UK: Woodhead Publishing Limited.

353 Corsetti, A., Gobbetti, M., Balestrieri, F., Paoletti, F., Russi, L., \& Rossi, J. (1998).

354 Sourdough lactic acid bacteria effects on bread firmness and staling. Journal of Food Science, $35563,347-351$.

356 Corsetti, A., Gobbetti, M., De Marco, B., Balestrieri, F., Paoletti, F., Russi, L., \&

357 Rossi, J. (2000). Combined effects of sourdough lactic acid bacteria and additives on bread

358 firmness and staling. Journal of Agricultural and Food Chemistry, 48, 3044-3051.

359 Corsetti, A. (2013). Technology of sourdough fermentation and sourdough

360 applications. In: Handbook on sourdough biotechnology (edited by M. Gobbetti, M. \& M.

361 Ganzle). Pp. 85-103. New York, US: Springer.

362 Dal Bello, F., Clarke, C.I., Ryan, L.A.M., Ulmera, H., Schober, T.J., Strom, K., et al.

363 (2007). Improvement of the quality and shelf life of wheat bread by fermentation with the

364 antifungal strain Lactobacillus plantarum FST 1.7. Journal of Cereal Science, 45, 309-318.

365 De Man, J. C., Rogosa, M., \& Sharpe, M. E. (1960). A medium for the cultivation of

366 lactobacilli. Journal of Applied Bacteriology, 23, 130-136.

367 Di Cagno, R., De Angelis, M., Lavermicocca, P., De Vincenzi, M., Giovannini, C.,

368 Faccia, M., Gobbetti, M. (2002). Proteolysis by sourdough lactic acid bacteria: effects on 
369 wheat flour protein fractions and gliadin peptides involved in human cereal intolerance.

370 Applied Environmental Microbiology, 68, 623-633.

371 Di Cagno, R., De Angelis, M., Auricchio, S., Greco, L., Clarke, C., De Vincenzi, M. et

372 al. (2004). Sourdough bread made from wheat and nontoxic flours and started with selected

373 lactobacilli is tolerated in celiac sprue patients. Applied Environmental Microbiology, 70, 374 1088-1096.

375 Di Cagno, R., Rizzello, C.G., De Angelis, M., Cassone, A., Giuliani, G., Benedusi, A., 376 et al. (2008). Use of selected sourdough strains of Lactobacillus for removing gluten and 377 enhancing the nutritional properties of gluten-free bread. Journal of Food Protection, 71, $378 \quad 1491-1495$.

379 EC (European Union Legislations, Commission Regulation). (2009). Concerning the 380 composition and labelling of foodstuffs suitable for people intolerant to gluten. EC n. $38141 / 2009,20$ January 2009. Official Journal of the European Union.

382 Edema, M. O., \& Sanni, A. I. (2008) Functional properties of selected starter cultures 383 for sour maize bread. Food Microbiology, 25, 616-625.

384 Hager, A. S., Wolter, A., Czerny, M., Bez, J., Zannini, E., Arendt, E. K., \& Czerny, M. 385 (2012). Investigation of product quality, sensory profile and ultrastructure of breads made 386 from a range of commercial gluten-free flours compared to their wheat counterparts.

387 European Food Research and Technology, 235, 333-344.

388 Houben, A., Hochstotter, A., \& Becker, T. (2012). Possibilities to increase the quality 389 in gluten-free bread production: an overview. European Food Research and Technology, 235, $390 \quad 195-208$.

391 International Organization for Standardization (1992) ISO 6611. Milk and milk

392 products - Enumeration of yeast and molds - Colony count technique at $25^{\circ} \mathrm{C}$. 
393 International Organization for Standardization (2003). ISO 4833. Microbiology of

394 food and animal feeding stuffs. Horizontal method for enumeration of microorganisms.

395 Colony count technique at $30{ }^{\circ} \mathrm{C}$.

396 Mariotti, M., Lucisano, M., Pagani, M. A., \& Ng, P. K. W. (2009). The role of corn

397 starch, amaranth flour, pea isolate, and Psyllium flour on the rheological properties and the

398 ultrastructure of gluten-free doughs. Food Research International, 42, 963-975.

399 Mariotti, M., Pagani, M.A., Lucisano, M. (2013). The role of buckwheat and HPMC

400 on the breadmaking properties of some commercial gluten-free bread mixtures. Food

401 Hydrocolloids, 30, 393-400.

402 Mezaize, S., Chevallier, S., Le Bail, A., \& De Lamballerie, M. (2009). Optimization of

403 gluten-free formulations for french-style breads. Journal of Food Science, 74, E140-E146.

404 Moore, M. M., Schober, T. J., Dockery, P., \& Arendt, E.K. (2004). Textural

405 comparison of gluten-free and wheat based doughs, batters and breads. Cereal Chemistry, 81, $406 \quad 567-575$.

407 Moore, M. M., Juga, B., Schober, T. J., \& Arendt, E.K. (2007). Effect of lactic acid

408 bacteria on properties of gluten-free sourdoughs, batters, and quality and ultrastructure of 409 gluten-free bread. Cereal Chemistry, 84, 357-364.

410 Moore, M., Dal Bello, F., \& Arendt, E. (2008). Sourdough fermented by Lactobacillus

411 plantarum FST 1.7 improves the quality and shelf life of gluten-free bread. European Food

412 Research and Technology, 226, 1309-1316.

413 Moroni, A. V., Dal Bello, F., \& Arendt, E. K. (2009). Sourdough in gluten-free bread-

414 making: an ancient technology to solve a novel issue? Food Microbiology, 26, 676-684.

415 Moroni, A.V., Arendt, E.K., \& Dal Bello, F. (2010a). Biodiversity of lactic acid

416 bacteria and yeasts in spontaneously fermented buckwheat and teff sourdoughs. Food

417 Microbiology, 28, 497-502. 
418 Moroni, A. V., Arendt, E. K., Morrissey, J. P., \& Dal Bello, F. (2010b). Development 419 of buckwheat and teff sourdoughs with the use of commercial starters. International Journal 420 of Food Microbiology, 142, 142-148.

421 Sanni, A. I., Onilude, A. A., \& Fatungase, M. O. (1998). Production of sour-maize 422 bread using starter cultures. World Journal of Microbiology and Biotechnology, 14, 101-106. 423 Schober, T.J., Bean, S.R., \& Boyle, D.L. (2007). Gluten-free sorghum bread improved 424 by sourdough fermentation: biochemical, rheological, and microstructural background. 425 Journal of Agriculture and Food Chemistry, 55, 5137-5146.

426 Torbica, A., Hadnadev, M., \& Dapčević, T. (2010). Rheological, textural and sensory 427 properties of gluten-free bread formulations based on rice and buckwheat flour. Food 428 Hydrocolloids, 24, 626-632.

429 Vogelmann, S. A., Seitter, M., Singer, U., Brandt, M. J., \& Hertel, C. (2009).

430 Adaptability of lactic acid bacteria and yeasts to sourdoughs prepared from cereals, 431 pseudocereals and cassava and use of competitive strains as starters. International Journal of 432 Food Microbiology, 130, 205-212.

433 Zannini E, Pontonio, E., Waters, D.M., \& Arendt, E.K. (2012). Applications of 434 microbial fermentations for production of gluten-free products and perspectives. Applied 435 Microbiology and Biotechnology, 93, 473-485.

436 


\section{$437 \quad$ Figure legends}

438

439 Fig. 1. Dough and bread preparation using gluten-free sourdough inoculum (a), dried gluten-

440 free sourdough inoculum (b), and bakery yeast (c).

441

442 Fig. 2. Rheofermentographic curves of dough development of GF mix A (a) or mix B (b).

443

444 Fig 3. Rate of staling of gluten-free doughs prepared from mix A (a) or mix B (b). The rate of

445 staling was calculated as [(Firmness after $n$ days - initial Firmness)/ initial Firmness], where $n$

446 represents the storage days. The detail in panel (b) represents an enlargement of the picture. 
448

449

450

451

452

453

454

455

456

d.b. $=$ dry basis
Table 1. Chemical composition of GF blends (g/100 g d.b.)

\begin{tabular}{ccc}
\hline & Mix A & Mix B \\
\hline Starch and soluble sugars & 82.4 & 79.0 \\
Protein & 5.8 & 7.0 \\
Fibre & 3.8 & 6.0 \\
\hline
\end{tabular}

457 
458 Table 2. Gluten-free sourdough characterization.

\begin{tabular}{lccc}
\hline & $\begin{array}{c}\text { Wheat Sourdough } \\
\text { (WS) }\end{array}$ & $\begin{array}{c}\text { Gluten-free } \\
\text { Inoculum (GFI) }\end{array}$ & $\begin{array}{c}\text { Dried gluten-free } \\
\text { Inoculum (DGFI) }\end{array}$ \\
\hline Moisture (g/100g) & $53.0 \pm 0.06$ & $49.1 \pm 0.41$ & $9.0 \pm 0.05$ \\
$\mathrm{pH}$ & $3.81 \pm 0.02$ & $4.11 \pm 0.04$ & $4.37 \pm 0.02$ \\
$\begin{array}{l}\text { Total titratable acidity } \\
\text { (ml NaOH 0.1M / 10g) }\end{array}$ & $8.78 \pm 0.32$ & $7.73 \pm 0.57$ & $7.20 \pm 0.52$ \\
Total Bacteria Count (CFU/g) & $8 * 10^{8}$ & $9 * 10^{8}$ & $8 * 10^{7}$ \\
LAB ( CFU/g) & $7 * 10^{8}$ & $8 * 10^{8}$ & $9 * 10^{6}$ \\
Yeast ( CFU/g) & $8 * 10^{7}$ & $9 * 10^{7}$ & $9 * 10^{6}$ \\
Gluten (mg/kg) & $>300$ & $<20$ & $<20$ \\
\hline
\end{tabular}

459

460 
461 Table 3. Dough rheofermentographic indices.

\begin{tabular}{|c|c|c|c|c|c|c|c|c|c|}
\hline & Leavening agent & $\begin{array}{c}\mathrm{Hm} \\
(\mathrm{mm})\end{array}$ & $\begin{array}{c}\mathrm{h} \\
(\mathrm{mm})\end{array}$ & $\begin{array}{l}\text { H'm } \\
(\mathrm{mm})\end{array}$ & $\begin{array}{c}\mathrm{Tx} \\
(\mathrm{min})\end{array}$ & $\begin{array}{c}\mathrm{CO}_{2} \text {-TOT } \\
(\mathrm{ml})\end{array}$ & $\begin{array}{c}\mathrm{CO}_{2} \text {-RET } \\
(\mathrm{ml})\end{array}$ & $\begin{array}{c}\mathrm{CO}_{2}-\mathrm{REL} \\
(\mathrm{ml})\end{array}$ & $\begin{array}{l}\mathrm{RC} \\
(\%)\end{array}$ \\
\hline \multirow{3}{*}{ Mix A } & BY & 80.3 & 57.8 & 89.6 & 91 & 1688 & 1547 & 141 & 91.6 \\
\hline & GFS & 69.6 & 69.6 & 31.9 & - & 1018 & 1011 & 7 & 99.3 \\
\hline & DGFS & 59.9 & 59.6 & 47.0 & - & 618 & 612 & 6 & 99.0 \\
\hline \multirow{3}{*}{ Mix B } & BY & 48.3 & 35 & 85.9 & 76 & 1812 & 1509 & 303 & 83.3 \\
\hline & GFS & 40.1 & 28.7 & 39.7 & 256 & 1237 & 1188 & 49 & 96.0 \\
\hline & DGFS & 44.7 & 44.7 & 2.5 & - & 1051 & 1040 & 10 & 99.0 \\
\hline
\end{tabular}

$463 \mathrm{Hm}=$ maximum dough height; $\mathrm{h}=$ final height of dough; H'm = maximum height of gaseous

464 production; $\mathrm{CO}_{2}-\mathrm{TOT}=$ total $\mathrm{CO}_{2}$ production; $\mathrm{CO}_{2}-\mathrm{RET}=\mathrm{CO}_{2}$ retained; $\mathrm{CO}_{2}-\mathrm{REL}=\mathrm{CO}_{2}$

465 released; $\mathrm{RC}=\mathrm{CO}_{2}$ retention coefficient; $\mathrm{Tx}=$ porosity time 
Table 4. Bread characteristics.

\begin{tabular}{|c|c|c|c|c|c|c|c|}
\hline & Leavening agent & $\begin{array}{l}\text { Weight } \\
\text { (g) }\end{array}$ & $\begin{array}{l}\text { Height } \\
(\mathrm{cm})\end{array}$ & $\begin{array}{l}\text { Specific } \\
\text { volume } \\
\left(\mathrm{cm}^{3} / \mathrm{g}\right)\end{array}$ & $\begin{array}{l}\text { Crumb } \\
\text { moisture } \\
(\mathrm{g} / 100 \mathrm{~g})\end{array}$ & $\begin{array}{c}\text { Crumb } \\
\mathrm{a}_{\mathrm{w}}\end{array}$ & Firmness $(\mathrm{N})$ \\
\hline \multirow{3}{*}{ Mix A } & $\mathrm{BY}$ & $55.9 \pm 1.3 b$ & $6.53 \pm 0.12 \mathrm{e}$ & $4.15 \pm 0.22 \mathrm{c}$ & $53.9 \pm 0.75 \mathrm{a}$ & $0.98 \pm 0.001 \mathrm{a}$ & $2.22 \pm 0.24 \mathrm{a}$ \\
\hline & GFS & $47.3 \pm 1.7 \mathrm{a}$ & $5.57 \pm 0.12 \mathrm{~d}$ & $4.12 \pm 0.14 \mathrm{c}$ & $54.1 \pm 2.7 \mathrm{a}$ & $0.98 \pm 0.005 \mathrm{a}$ & $4.86 \pm 1.51 \mathrm{ab}$ \\
\hline & DGFS & $54.5 \pm 0.6 b$ & $5.23 \pm 0.06 \mathrm{c}$ & $2.97 \pm 0.07 \mathrm{a}$ & $54.6 \pm 0.25 \mathrm{a}$ & $0.99 \pm 0.002 \mathrm{a}$ & $10.58 \pm 0.53 d$ \\
\hline \multirow{3}{*}{ Mix B } & BY & $54.8 \pm 0.9 b$ & $4.97 \pm 0.12 b$ & $3.22 \pm 0.10 \mathrm{~b}$ & $53.8 \pm 0.73 \mathrm{a}$ & $0.99 \pm 0.006 \mathrm{a}$ & $6.63 \pm 1.26 b c$ \\
\hline & GFS & $55.9 \pm 0.2 b$ & $4.97 \pm 0.06 b$ & $3.10 \pm 0.08 b$ & $53.8 \pm 0.53 \mathrm{a}$ & $0.98 \pm 0.005 \mathrm{a}$ & $7.33 \pm 1.15 \mathrm{c}$ \\
\hline & DGFS & $58.1 \pm 0.7 \mathrm{c}$ & $4.70 \pm 0.10 \mathrm{a}$ & $2.95 \pm 0.06 \mathrm{a}$ & $54.9 \pm 0.16 \mathrm{a}$ & $0.98 \pm 0.004 \mathrm{a}$ & $6.86 \pm 1.20 \mathrm{c}$ \\
\hline
\end{tabular}

Means and standard deviations followed by different letters in a column are significantly different $(\mathrm{LSD} ; \mathrm{p}<0.05)$ 


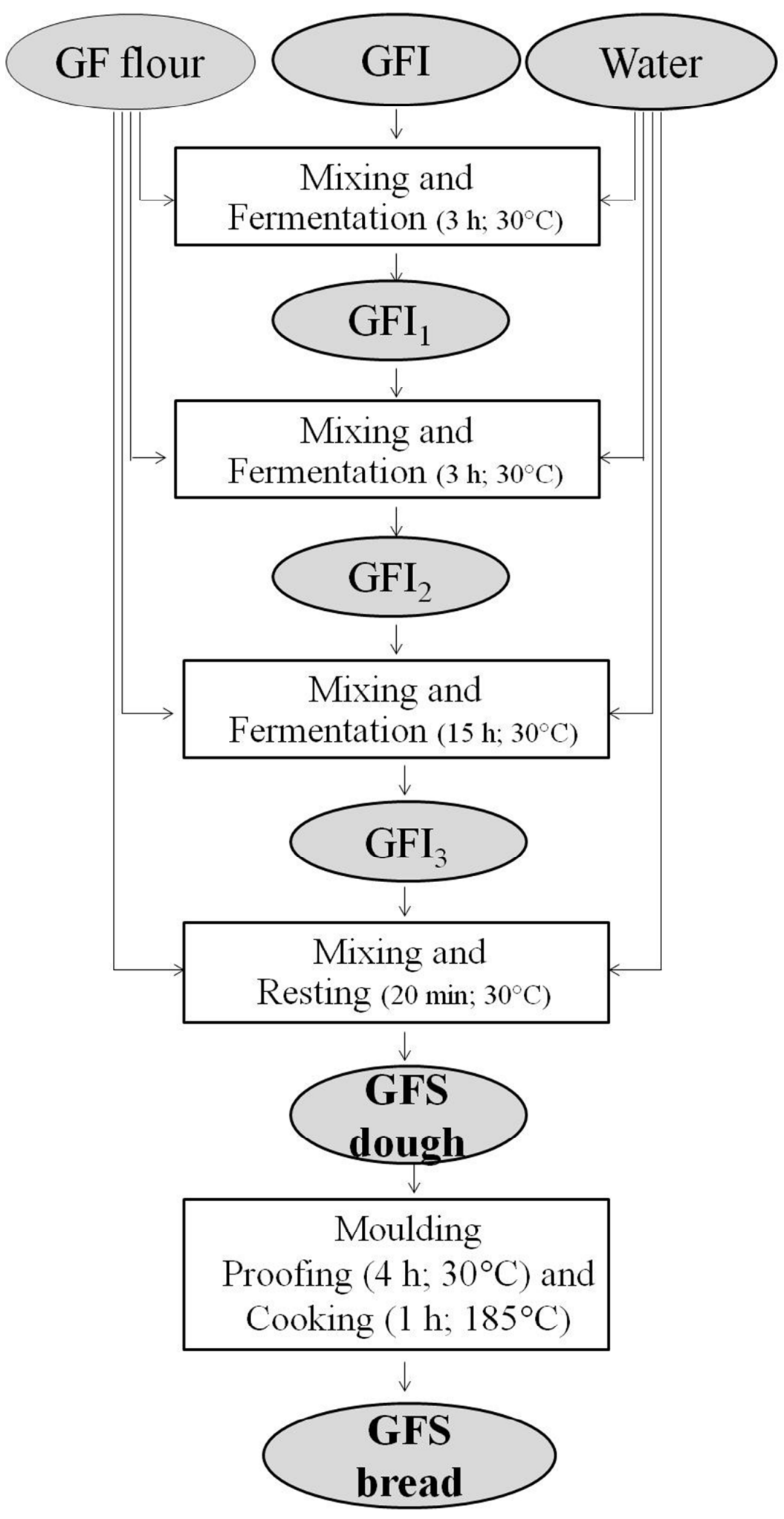

(a) 


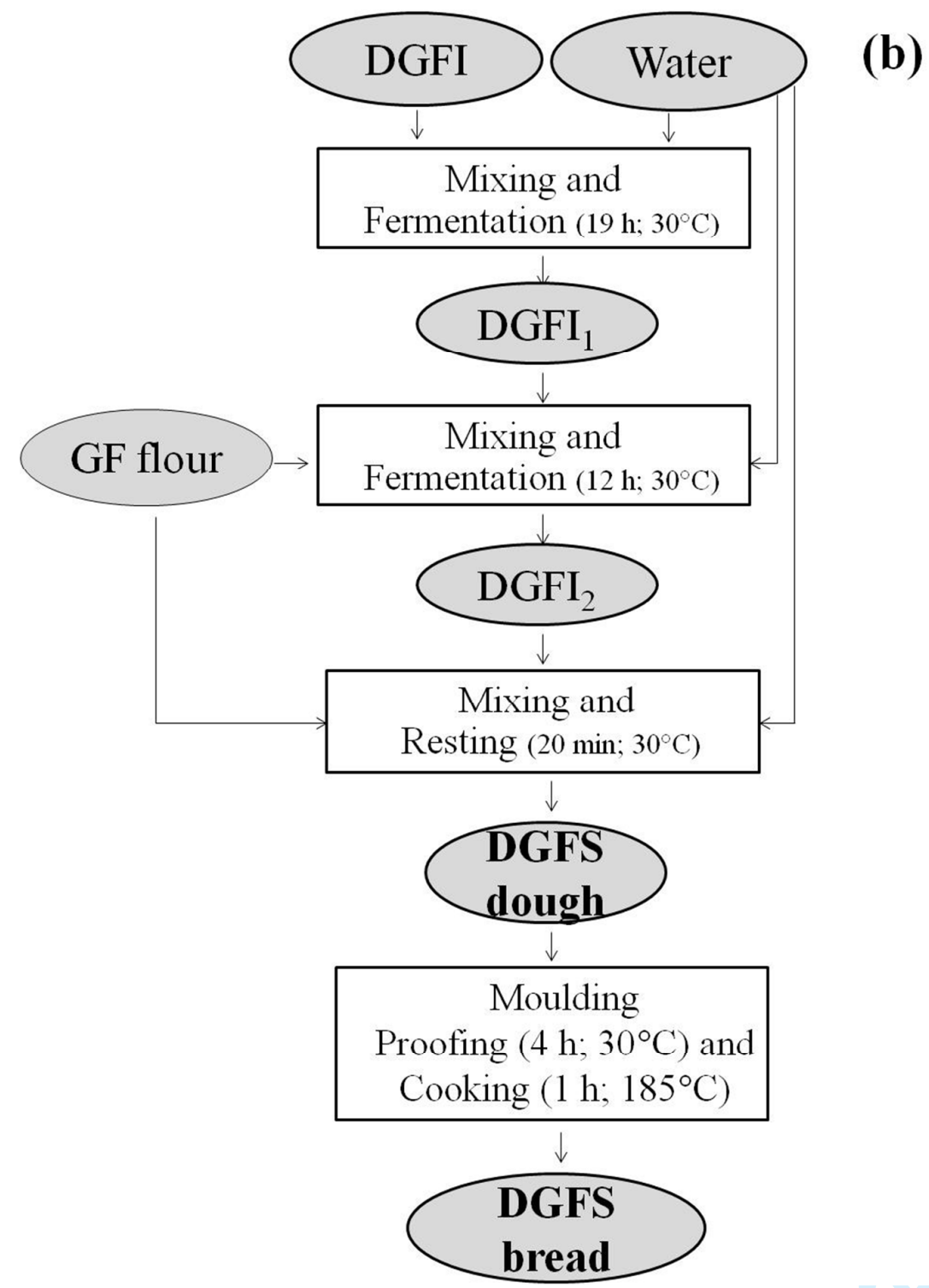




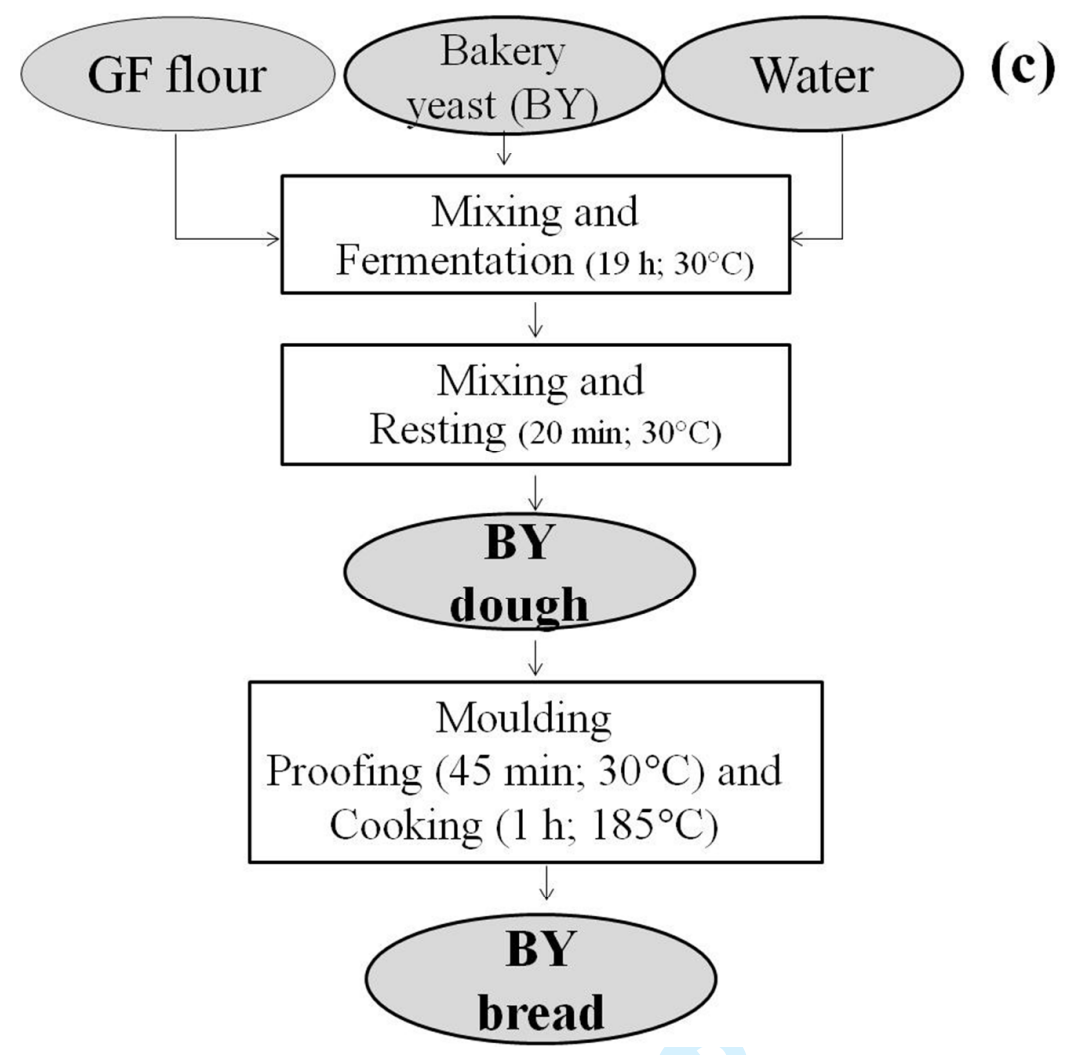

Fig. 1. 

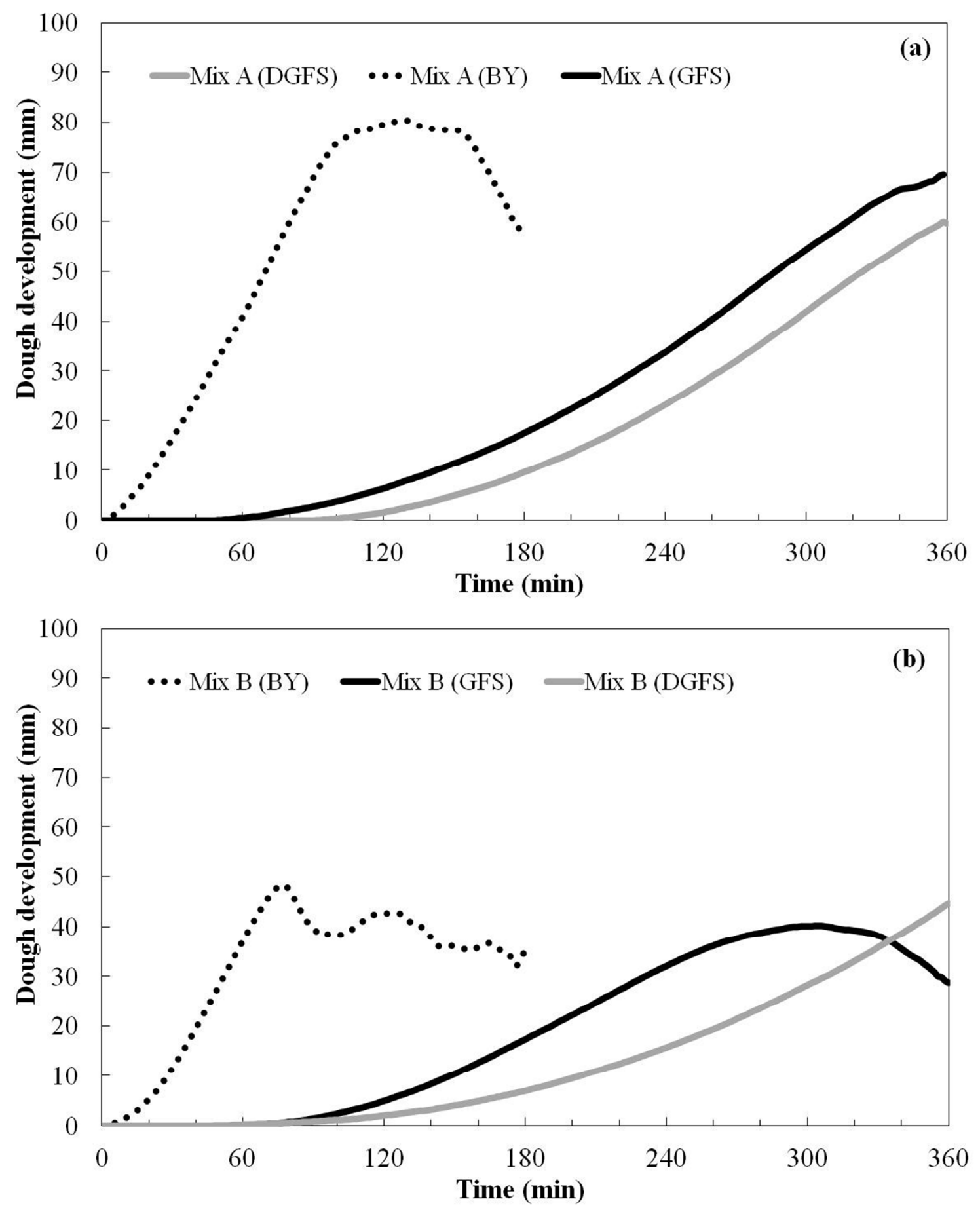

Fig. 2 

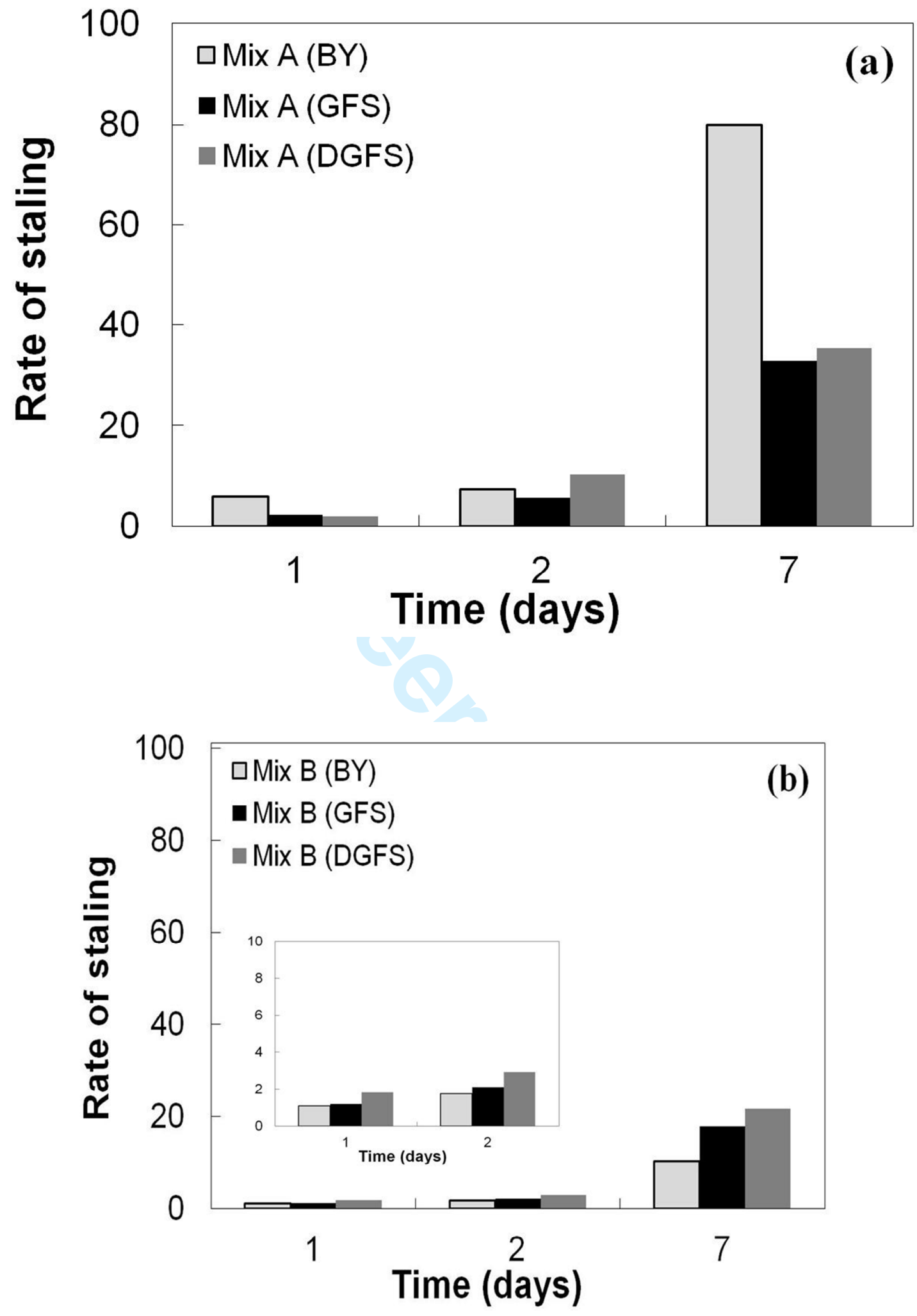

Fig. 3. 